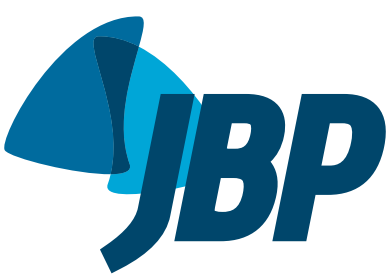

\title{
The need for a balance between highly prevalent diseases and neglected diseases
}

\author{
Rogério Souza $a^{1,2, a}$
}

Some topics can be considered as being highly represented in the JBP, in particular those related to mycobacterial diseases and obstructive airway diseases. That could not be otherwise, given that those are major public health problems and, as such, deserve to be emphasized, as well as because intervention policies targeting such diseases have an impact on a significant number of patients.

Among mycobacterial diseases, tuberculosis undoubtedly garners the most attention. In recent years, the JBP has published dozens of articles providing details on the epidemiology, diagnosis, and treatment of tuberculosis. ${ }^{(1-3)}$ Likewise, the various aspects of COPD and asthma have been widely debated in our Journal. ${ }^{(4,5)}$ If the intention of an official organ of dissemination of a scientific society is to keep its constituents up to date on the main aspects of the field in question, these data suggest a way forward.

There are numerous highly prevalent conditions that are underrepresented in our Journal. Perhaps the most striking examples are sleep-related breathing disorders and venous thromboembolism. Despite the epidemiological importance of both, the JBP has published an insignificant number of articles on those topics in the last decade. That raises the following question: is this low representativeness a reflection of the current state of research on those topics in our country, or (worse) does it reflect a progressive loss of interest or reduced participation of the members of our scientific society in these areas of activity? If the first hypothesis can be refuted on the basis of articles published in the international literature by highly cited Brazilian researchers, the second should be the subject of reflection and ongoing efforts by all of the parties involved. There is also a third, intermediate, hypothesis that could explain the low representativeness of those topics in the JBP: it is possible that cutting-edge research on those topics is being conducted but that the scope of that research is still too limited to prompt submission for publication in high-impact journals or in those with a more regional readership.

Despite the fact that it is not possible to provide a direct, objective answer to the question posed above, we have sought to increase the exposure of highly prevalent conditions that were previously underrepresented, in order to provide the reader with a reliable means of remaining up to date, as well as to raise awareness of the research groups existing in Brazil, particularly those working in the areas of interest. Therefore, diagnostic and therapeutic guidelines have both been discussed in depth. ${ }^{(6-8)}$ In the near future, it might be worthwhile to utilize the JBP as a forum for discussion regarding the true role of the members of our scientific society in such areas, as well as to understand the need to create continuing education sections that contemplate those topics. In addition, it is important to analyze publications in these areas over time as a way of determining whether their exposure in recent years has had any significant impact.

In the JBP, not only has there been an increase in the publication of articles related to clinical conditions that are more rare or poorly investigated but such articles have also become some of the most widely cited JBP articles. $(9,10)$ Nevertheless, the approach chosen was to seek to discuss the rarer situations through review articles. The aim was to make knowledge of poorly explored topics more accessible. Interstitial lung diseases and the evaluation of respiratory muscle function are clear examples of the demand for using the JBP as a resource for continuing education, an approach that could be translated directly to clinical practice. ${ }^{(11,12)}$

Maintaining a balance between the unequivocal interest in the most prevalent diseases and the need to explore incipient areas, including the exposure of conditions that are more rare, as well as the need to increase the representativeness of our Journal, is not a simple task and was the object of reflection in another editorial published previously in the JBP. ${ }^{(13)}$ However, it is more than necessary in an environment such as ours, in which there is considerable heterogeneity in terms of the availability of resources and access to knowledge. The fruits of this attempt, initiated four years ago, will be known only in the (not too distant) future ${ }^{(14)}$. Nevertheless, it was undoubtedly a journey of absolute learning and exchange with the most distinguished researchers in Brazil, a significant number of whom are on the editorial board of our Journal, having been active participants in this journey. All of those researchers have our unequivocal, eternal gratitude. It is also certain that this path is as broad as the interest aroused in the reader-that is perhaps the key to growth: to generate interest in the most robust aspects of the field of pulmonology in Brazil, which has been consistently growing. Everyone involved has worked to see that growth reflected in our Journal, which now passes into the hands of its new Editor-in-Chief, Bruno Baldi, who has long been a member of its editorial board. I trust that his editorship will be well received and that he will enjoy the collaboration of all parties, in order to continue to expand the dissemination of the best of what is produced in respiratory medicine in Brazil. 


\section{REFERENCES}

1. Lacerda TC, Souza FM, Prado TND, Locatelli RL, Fregona G, Lima $R C D$, et al. Tuberculosis infection among primary health care workers J Bras Pneumol. 2017;43(6):416-423. https://doi.org/10.1590/s180637562016000000211

2. Pinto $M$, Entringer $A P$, Steffen $R$, Trajman $A$. Cost analysis of nucleic acid amplification for diagnosing pulmonary tuberculosis, within the context of the Brazilian Unified Health Care System. Bras Pneumol. 2015;41(6):536-8. https://doi.org/10.1590/s180637562015000004524

3. Rabahi MF, Silva Júnior JLRD, Ferreira ACG, Tannus-Silva DGS Conde MB. Tuberculosis treatment. J Bras Pneumol. 2017;43(6):472 486. https://doi.org/10.1590/s1806-37562016000000388

4. Fernandes FLA, Cukier A, Camelier AA, Fritscher CC Costa CHD, Pereira EDB, et al. Recommendations for the pharmacological treatment of COPD: questions and answers. J Bras Pneumol. 2017;43(4):290-301. https://doi.org/10.1590/s180637562017000000153

5. Cardoso TA, Roncada C, Silva ERD, Pinto LA, Jones MH, Stein RT, et al. The impact of asthma in Brazil: a longitudinal analysis of data from a Brazilian national database system. J Bras Pneumol. 2017;43(3):163 168. https://doi.org/10.1590/s1806-37562016000000352

6. Fernandes CJ, Alves Júnior JL, Gavilanes F, Prada LF, Morinaga LK, Souza R. New anticoagulants for the treatment of venous thromboembolism. J Bras Pneumol. 2016;42(2):146-54. https://doi. org/10.1590/S1806-37562016042020068

7. Beltrami FG, Nguyen XL, Pichereau C, Maury E, Fleury B, Fagondes S. Sleep in the intensive care unit. J Bras Pneumol. 2015;41(6):539 46. https://doi.org/10.1590/s1806-37562015000000056
8. Lei $\mathrm{Q}, \mathrm{LV} Y$, Li K, Ma L, Du G, Xiang Y, Li X. Effects of continuous positive airway pressure on blood pressure in patients with resistant hypertension and obstructive sleep apnea: a systematic review and meta-analysis of six randomized controlled trials. J Bras Pneumol. 2017;43(5):373-379. https://doi.org/10.1590/s180637562016000000190

9. Freitas CS, Baldi BG, Araújo MS, Heiden GI, Kairalla RA, Carvalho $\mathrm{CR}$. Use of sirolimus in the treatment of lymphangioleiomyomatosis: favorable responses in patients with different extrapulmonary manifestations. J Bras Pneumol. 2015;41(3):275-80. https://doi. org/10.1590/S1806-37132015000004553

10. Gavilanes F, Alves JL Jr, Fernandes C, Prada LF, Jardim CV, Morinaga $L T$, et al. Left ventricular dysfunction in patients with suspected pulmonary arterial hypertension. J Bras Pneumol. 2014;40(6):609-16. https://doi.org/10.1590/S1806-37132014000600004

11. Caruso $P$, Albuquerque $A L$, Santana $P V$, Cardenas $L Z$, Ferreira $J G$. Prina $E$, et al. Diagnostic methods to assess inspiratory and expiratory muscle strength. J Bras Pneumol. 2015;41(2):110-23. https://doi.org/10.1590/S1806-37132015000004474

12. Baddini-Martinez J, Baldi BG, Costa CH, Jezler S, Lima MS, Rufino R. Update on diagnosis and treatment of idiopathic pulmonary fibrosis. J Bras Pneumol. 2015;41(5):454-66. https://doi.org/10.1590/S180637132015000000152

13. Souza R. JBPand bibliometric indices. J Bras Pneumol. 2017:43(4):247248. https://doi.org/10.1590/s1806-37562017000400002

14. Souza R. Consolidating in the present, with an eye to the future. J Bras Pneumol. 2016;42(6):399-400. https://doi.org/10.1590/s180637562016000600002 